\title{
Architectural Implications for Dogs
}

\author{
Anjali V. Narad, Vaishnavi J. Chaudhari \\ Assistant Professor, Radhikatai Pandav Institute of Architecture,Nagpur,R.T.M.Nagpur University,India \\ Jr. Architect, CREDO Architects, Ahemdabad, Gujarat, India.
}

\begin{abstract}
Dogs are always identified as a subspecies of a wolf, but the history of its existence is still unsolved. Though many researchers stated the origin of dogs came from the wolf fossil found in Europe several years ago. If the history of domestication is analysed, then it can be said that dogs are the first species to be domesticated on the Earth. In the past few decades' dogs' evolution and its involvement in humans life is so meteoric that they became a part of our lives. Dog being the most trustworthy and socialised species on this planet made humans to domesticate them in fields for various activities. This became one of the major reasons to boost economy as well as to develop ones physical and mental condition. Similar to the humans, dogs also have a great list of requirements on basis of their physical and psychological conditions which made it possible to design a dwelling for a dogs living. Sir. BRUCE FOGLE in his book "THE DOGS MIND-Understand Your Dogs Behaviour" explained about the anatomy, physiology and the psychology of a dog.

Architecture is all about designing a life and this paper would be an endeavour to design spaces for dogs to strengthen their relationship with humans and environment.
\end{abstract}

Keywords: Domestication, psychology, anatomy, physiology.

\section{Introduction}

With the meteoric improvement of physical condition of humans the mental condition is also growing rapidly. Having a pet now a days is very common in the society. They bring joy and enrich one with healthy environment. One can play with them, talk to them, go for a walk, handicap people can keep them as a companion too. After all this its very sad to see many abandoned dogs roaming on roads. The reason behind the presence of stray dogs may be the inappropriate knowledge need to keep pets. In many cases without any mistakes these Speechless animals become abandoned and

\section{History of Dogs}

The history of dog's existence is not clear yet, but their nuclear DNA says that about 11,000 16,000 years ago dogs were domesticated mostly by hunters and they became the first species of animals to be domesticated. With the rise of agriculture, farmers started to keep pets for security and thus dogs got evolved from farm to sometimes get into accidents, attack people and even carry diseases which are unhealthy for human society. There are few lucky dogs also who send to rehabilitation centre are where they are taken care.

According to the 2018 records of Nagpur Municipal Corporation 81188 numbers of stray dogs and 15000 numbers of pet dogs are enrolled. This overpopulation of $\operatorname{dogs}$ needs to be controlled with a structured approach and Architects have an ability to solve the issues regarding wildlife and homeless animals.

sofa. The early role of dogs was just to protect hunters during hunting and help farmers to carry loads and benefit themselves with their security skills.

According to the changing lifestyle of dogs in the society two major trends had been observed. The one is 'co modification', i.e. training dogs with respect to their skills for the benefits of human 
society and another is 'broadening', i.e. the way dogs became a part of the family and is now treated as another member with the provision of all the luxurious facilities given to a human. A dog involvement in human's life is on such a high scale that for some people it became a matter of prestige and style. In higher society the quality of dogs lifestyle changes according to the owners lifestyle and bank balance, but in middle class society though the quality of lifestyle may degrade proportional to the economical conditions but the owner is always self sufficient in providing the basic needs to their pets. This shows that pets have an equal importance in every owner's life irrespective to the quality of society they are living in.

In last few decades humans grew so fast that they made each and every thing available for themselves and same with the pets. There was a time when pets were treated just like another animals but today they have many facilities. The love for pets took such a place that today they have spas, clinics, shops, parks, dog shows, boarding facilities, restaurants, etc. Not just a pet but dog proved to be capable enough in many fields. Today they had been recruited in army, police and are trained for shows and security too.

\section{Physiology and Psychology of Dogs}

According to Sir. BRUCE FOGEL, if dogs are isolated from humans till 12 weeks from the birth it becomes hard for them to establish a good companionship with humans. During this 12 weeks

The period of 6-8 weeks is most critical for them. These 12 weeks are divided into 3 different stages of a dogs physiological and psychological growth and they are-1. Neonatal period (0-2 weeks)

2. Transitional period (2-4 weeks)

3. Socialization period-

- To dogs (4-6 weeks)

- To humans (4-12 weeks)

Neonatal period is mostly the maternal period where the mother's behaviour influences the pups. During the period both mother and pups imprint each other in their minds. In case of development their sensitivity to touch, to pain, to temperature and to taste, hearing, vision and temperature regulation are still undeveloped. However, this may develop rapidly in next 2 weeks i.e. in transitional period. In transitional period pups develop their senses to hunger and starts asking to regulate meal. Then comes the socialization period where dogs matured to near adult up to 4 weeks of age and their senses also gets developed. In socialization period.i.e. till 6 weeks and after that dogs needs more social interaction and hence they require more circulation space to play as it stimulates communal behaviour. After the age of 6 weeks the epimeletic behaviour of mother may ends but the et-epimeletic behaviour of dogs continues to the end of their lives. With respect to the above information below in figure. 1 and table no. 1 to 3 is the anthropometry of dogs which shows the minimum and maximum circulation of a dog needed in a specific period of age. This diagram and table got finalized after studying the physiological growth of 11 dogs breed which can easily be found in India. These 11 breed consist of both small and large dogs.i.e. German shepherd, Golden retriever, Great dane, Labrador retriever, Beagle, Bull dog, Cocker spaniel, Doberman, Pomeranien, Rotwiller and Pug. The dimensions given in the table are approximate and it may differ according to the speed of growth.

Dogs are sophisticated and they have this unique medium of communication called as mute signalling which gets developed with the time. With this medium of communication and physics it's obvious that we can't produce a dog that can unlock the door or open the water bottle; we need to design a door without a lock or water bottle specifically for dogs. 
Table.no.2
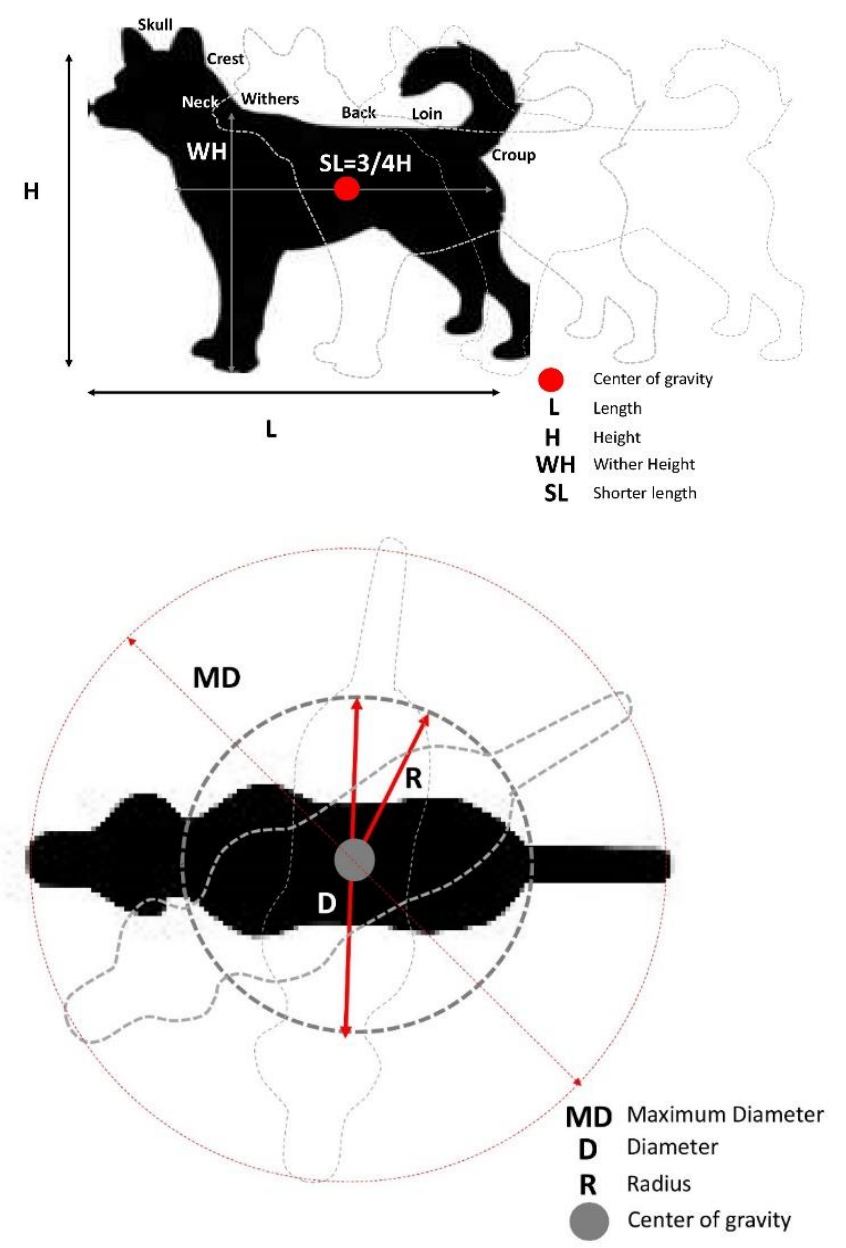

Figurre.1. Anthropometry of dogs

\begin{tabular}{|l|l|l|}
\hline \multicolumn{3}{|c|}{ CIRCULATION CHART } \\
\hline LEGEND & MINIMUM & MAXIMUM \\
\hline $\mathrm{H}$ (height) & $25 \mathrm{~cm}$ & $112 \mathrm{~cm}$ \\
\hline L (length) & $40 \mathrm{~cm}$ & $122 \mathrm{~cm}$ \\
\hline WH ( wither height) & $15 \mathrm{~cm}$ & $78 \mathrm{~cm}$ \\
\hline $\begin{array}{l}\text { MD (maximum } \\
\text { diameter) }\end{array}$ & $70 \mathrm{~cm}$ & $165 \mathrm{~cm}$ \\
\hline D (diameter) & $25 \mathrm{~cm}$ & $90 \mathrm{~cm}$ \\
\hline R (radius) & $12.5 \mathrm{~cm}$ & $45 \mathrm{~cm}$ \\
\hline
\end{tabular}

Table.no.1

\begin{tabular}{|l|l|l|}
\hline \multicolumn{3}{|c|}{ CIRCULATION CHART FOR PUPS (1-6 WEEKS) } \\
\hline LEGEND & MINIMUM & MAXIMUM \\
\hline H (height) & $25 \mathrm{~cm}$ & $50 \mathrm{~cm}$ \\
\hline L (length) & $40 \mathrm{~cm}$ & $55 \mathrm{~cm}$ \\
\hline WH ( wither height) & $15 \mathrm{~cm}$ & $35 \mathrm{~cm}$ \\
\hline MD (maximum diameter) & $70 \mathrm{~cm}$ & $80 \mathrm{~cm}$ \\
\hline D (diameter) & $25 \mathrm{~cm}$ & $35 \mathrm{~cm}$ \\
\hline R (radius) & $12.5 \mathrm{~cm}$ & $15 \mathrm{~cm}$ \\
\hline Total area & $0.38 \mathrm{sqm}$ & $0.5 \mathrm{sqm}$ \\
\hline
\end{tabular}

\begin{tabular}{|l|l|l|}
\hline \multicolumn{3}{|c|}{ CIRCULATION CHART FOR ADULT (ABOVE 6} \\
WEEKS)
\end{tabular}

Table.no.3

\section{Interrelationship}

There had been numerous researches done on this topic but architectural implications to encourage the human-animal, human-environment and animal-environment relationships are not much discussed. The following are the types of relationships and the proposal designs applicable to enhance them:

\section{Human - Animal Interrelationship}

The human - animal interrelationships are proportionally beneficial to both of them. In many many researches it has been observed that walking with dogs, playing and petting them reduces many physical and mental problems in humans as well as in dogs. Dogs also proved to be a therapist. Under AAT.i.e. Animal Assisted Therapy dogs are involved as personal healers for patients. Amy McCullough, Ashieigh Ruehrdanz and Molly Jenkins in their paper titled "The use of dogs in hospital settings" explain the benefits of dog's involvement in hospitals under AAT program. According to them dog can reduce the pain, stress and anxiety of the patient and provides a friendly atmosphere in the hospital. In our neighbourhood we have some open spaces and if it gets accessible for dogs, humans walking rate may increase and addition to this some dog friendly spaces to sit and socialize can be designed as shown in figure. 2 . 


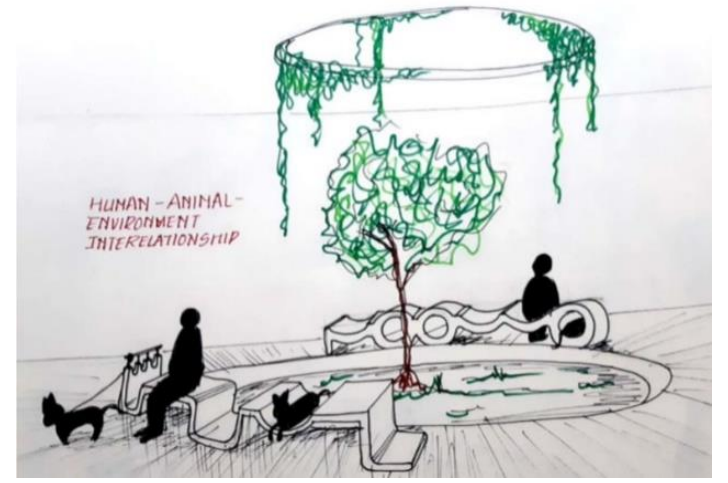

Figure.2.Seatings for humans and dogs

Some breeds of dogs are hyperactive and need playing tools to jump, run and crawl. An idea to design a punctured wall in gardens and other open spaces can excite dogs to come and play which eventually increase human-human, animal-human and human environment interaction(figure.3.).

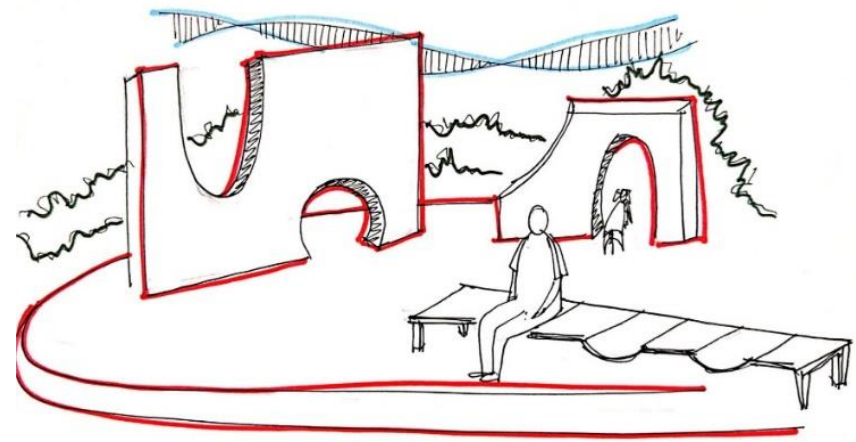

Figure.3.Punctured wall for dogs to jump and crawl

Dogs being the most socialized animals can get adversely affected if dwelled in an enclosed environment. With the growing age and body of dogs their anxiety also increases and hence social interaction with humans and other animals is important. As shown in figure.4. dogs dwelling can be designed in such a way that they can enjoy fresh air, direct sun light and can also interact with humans. In figure.4. a glass partition is provided between a corridor and a dogs dwelling in kennels, obviously one can't play, talk or grab a dog but a vision of having humans in the surrounding is also a part of socialization.

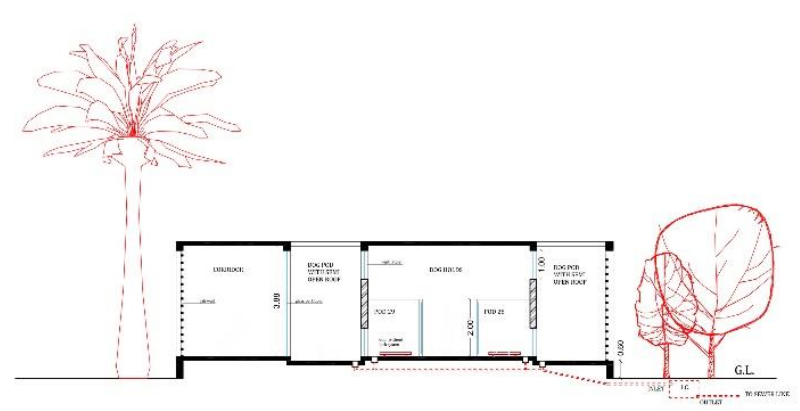

Figure.4.Section of a indoor dogs dwelling in the kennel

\section{Animal - Environment Interrelationship}

Similar to animal human connections dog has a great relationship with environment too. The dwelling they live in has positive as well as negative impact on their mental condition. For example, when dogs are left alone in an enclosed house they become more anxious and if they are provided with a small open air garden they stays calm and healthy. In kennels the environment they have is already stressful for dogs just because of accomoding numerous dogs in a common hall. In India it has been observed that on many places the kennel architecture is practiced in a wrong way. The pods or dwelling units provided for dogs are neither according to the standards nor they have proper circulation and sanitation. In many researches it has been found that dogs develop great relationships with the foliage and more the foliage in garden the more dogs enjoy to walk and play with their masters. The backyard garden or parks landscape attracts birds and butterflies which excites the dog and they don't need any toys to stay fit and active. Below in figure.5.is the rough idea for an outdoor dwelling in the kennel.

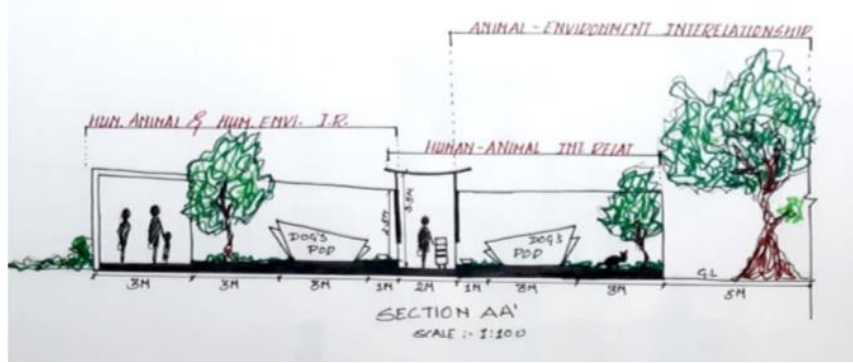

Figure.5. Dogs outdoor dwelling in the kennel

Dogs are a great sniffer and this quality of them is highly used in military and police services. For finding food and protecting the master dogs use this ability a lot. It seems hard to believe that dogs don't have a sense of taste, they recognize eatables on basis of 
odour and texture. Dogs are excellent in finding ways to their destination but still some fails in it. Designing a maze for dogs in parks may help to train a dog and hence a non-professional trainer can also take their dogs to the park and train there. As shown in figure.6. And 7 a maze can be designed with seating furniture's also.

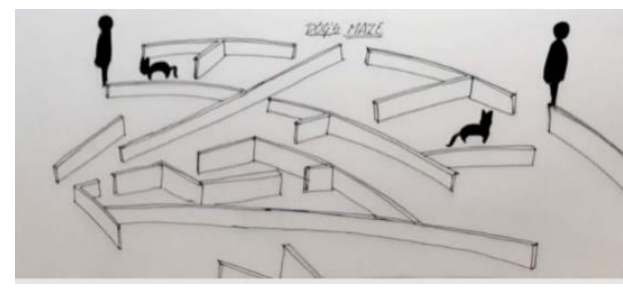

Figure.6. Dogs maze

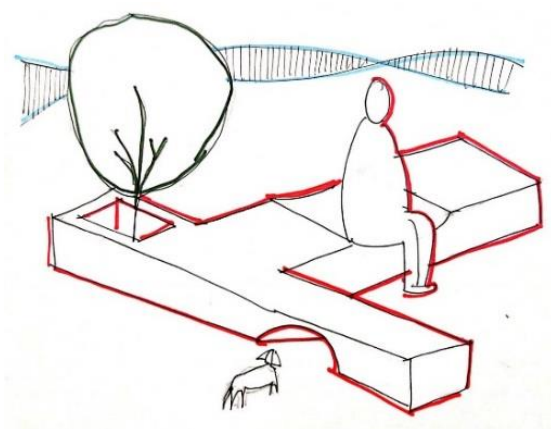

Figure.7. Seating in dogs maze

Every dog practices digging commonly and that's the part of their personality. One can't change their habits as it is important for their physical growth, but can definitely design the spaces in the way they want. While designing play areas for dogs sandy grounds are mandatory and this is the only way to avoid the foliage destruction.

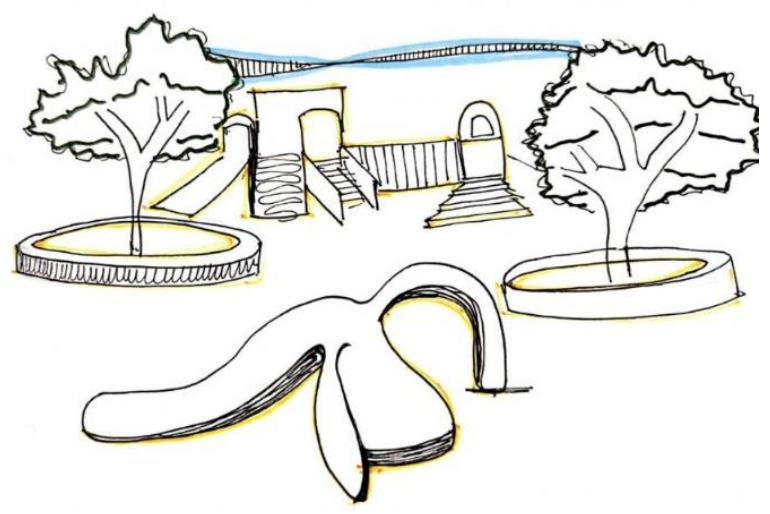

Figure.8. Sandy play area with plants and playing furniture's

\section{Human - Environment Interrelationship}

From ancient time till now humans and their surrounding has changed a lot. Once animals use to rule the planet and now humans do. There was a time when human society attempt to develop technology for their own security and luxury and now they develop it to secure animals and nature, hence in ancient time humans surrounding includes animals, birds and trees which today got replace by skyscrapers, tower and vehicles. Humans environment was the main reason for healthy and long life of living beings. Many researches proved that natures sound like birds murmuring, winds, dropping water, flowing rivers, sea waves, animal howling, etc. keep humans mind calm, relax and free from anxiety but today this immense pollution doesn't let nature come to us. If human's psychology kept in mind then these natural elements can get adopted again by designing more recreational spaces in the society can help humans get rid of psychological disorder.

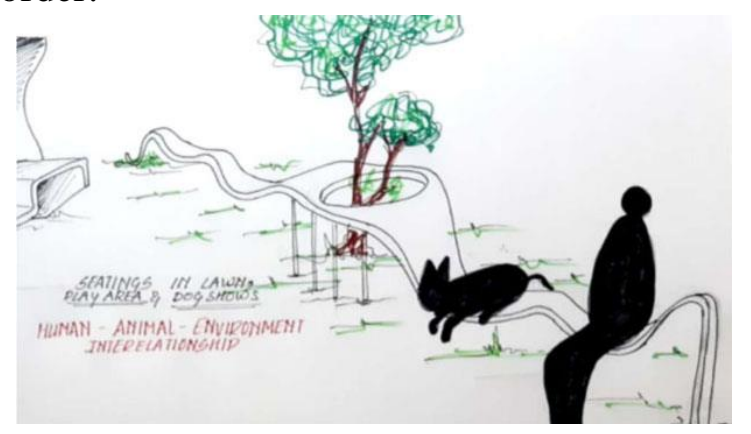

Figure.9. Assembling plants and seating together to encourage human-environment interrelationship

\section{Landscape For Dogs}

When it comes to a dog, similar to the humans, vision and height of dogs plays a very important role in landscape. While talking about the vision dogs have a scope of 250 degree vision unlike the humans with 180 degrees. Hence, dogs have a more side view than humans and this makes it important to provide a proper landscape beside the walkways. In landscaping types of plants may differ according to the users. As in this case there are two types of users .i.e. humans and dogs and hence it is obvious to have a difference in height of vision too. Humans have maximum height of $1.7 \mathrm{~m}$ where as dog has of $1.12 \mathrm{~m}$. In this case if trees like Ashoka and bottle palm get planted then humans would be pleased but due to the lower height, dogs will have only trunk view. In order to tackle this problem planting shrubs is important because shrubs have a low height and dogs could get a pleasing view while waking and this would indirectly affect the walking time of the dog as 
well as humans. The more amiable landscape is, the more humans and dogs desire to enjoy.

The selection of plants needs to be done according to the dog's likes and dislikes. For example, dogs have an active state of mind hence they can stuck anywhere in the plants, in order to avoid such type of situations thorny plants like cactus and some type of palm should be avoided.

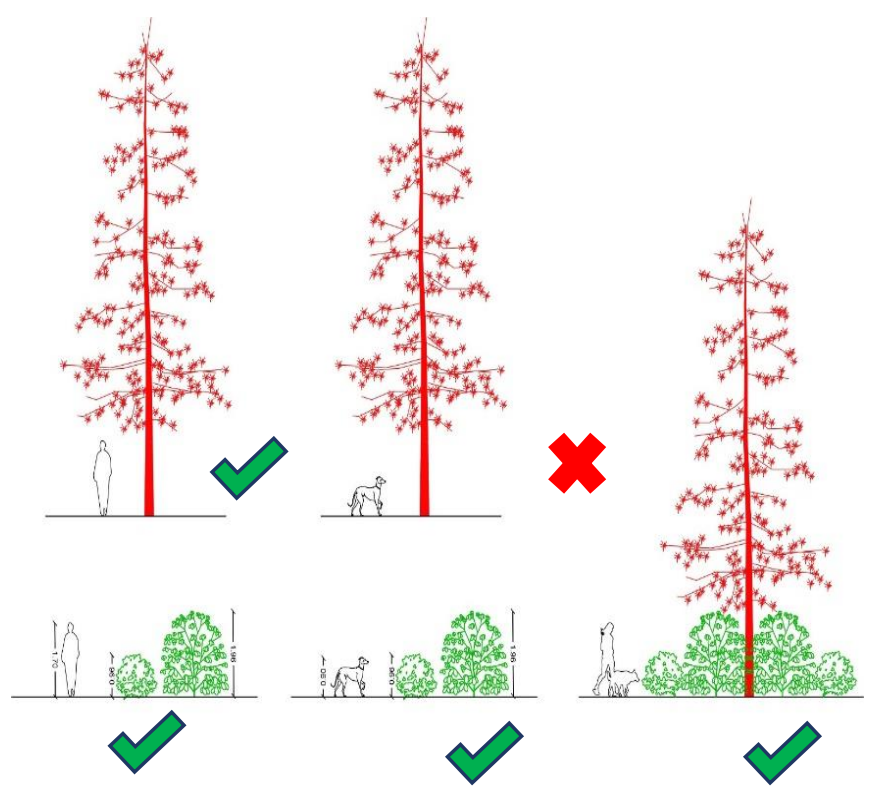

Figure.9. Landscape for dogs

\section{Human Animal Behavior}

Behaviour pattern of humans to animals and animals to humans differs in many cases, it also differs for domestic and wild animals. Domestic animals like dog, cat, hamster, guinea pig, rabbit, etc. are always dominated by humans and some where they have an extraordinary ability to socialize with humans as their habitat is not reserved any where unlike the wild animals. Due to their socialization and eating habits they can easily adjust with humans. Most of the domestic animals are vegetarian and hence it becomes pocket friendly to pet them. When it comes to training their socialization with humans makes it easy to train them because in this relationship human becomes a dictator for them, but dictatorship also has some limits. Similar to human's domestic animals needs freedom or else they ruin the environment. Dogs always try to follow their masters, it has observed that dogs like and dislike mostly depends on their masters. Their sense informs them about every emotional condition of their master and exactly like humans they try to help by doing annoying and funny activities to rebost them. It may sound funny but when sometimes dog fells ignored by the master they act to get sick just to grab attention.

Wild animals are restricted to pet every where but still in some countries like UAE the billionaire practice this domestication to showcase their prestige, but this behaviour to them is against their nature, however it has ban now. Animals like lion, tiger, hyena, Black Panther, cheetah, etc. are carnivores, even humans are food to them, but if they get socialize with humans from childhood, then only, one can become a part of their habitat. In this relation humans are friend to them only as long as they get love and respected. Here wild animals are the dictators and humans are the one who need to get dominated. They can't resist dominance from humans. If humans want to get in their territory then they need to be their childhood friend. Wild animal psychology is little bit different from the domestic animals. Being a friend to wild animal means actually being like them. If they drink water from pond then one need to showcase them the same. After having dinner wild animals lick each other for grooming and it's the sign of care, affection and friendship and in case any human meets them in the situation, the person needs to act grooming with hands. One needs to roar with them,

crawl, run and play the same way wild animals do to gain their trust. But this wild nature of them doesn't mean that architects can't design anything for them, actually they also need some structures to play. In African jungles where most of the wild animals stay in captivity has designed few wooden structures for them. The only difference between the domestic and wild designing is in the scale and load resistance of the design.

\section{Conclusion}

In the busy schedule of humans unknowingly money becomes the top most priority for humans and this affects their physical and mental health in many ways. In order to tackle work pressure 
humans generally pet animals and this act as a therapy to them. There are many dog lovers in the world and they love to take them for outing. If such open spaces, explained above, get designed in public parks, society gardens, office gardens, rehabilitations, hospitals, etc. psychological and physiological condition of humans will improve rapidly. Old people will find a companion, office productivity will increase, patients recover rate will gear up. The healthy stray dogs can get trained and allotted with shelters on such places so that the stray dogs population gets controlled and they may also get a healthy life. This attempt could increase the amount of dog adoption and an abandoned animal will find a family.

\section{References}

[1] Human animal interaction research in school settings:current knowledge and further direction, AERA open, july-september 2017, vol 3 , no 3 ,pp1-9.

[2] Street dogs at the interaction on colonialism and informality: 'subeltaren animism' as a posthuman critique of indian citizen, Dsociety and space, 2017, vol 35(3), 475-494.

[3] Preference for breed and feeding practice for dog rearing in Nagpur city of Maharashtra, veternary world, vol 2(3), 109-110.

[4] Socio-economic status of dog owners in corporation of Chennai, Tamilnadu, international journal of current research, vol 7 , issue 11, pp 22605-22606, november 2015.

[5] A human landscape- reconecting human and animals through landscape for animals for animal shelter. D A Zhang

[6] Redefining shelter:fostering human/canine relationship through a new typology by Sabrina Nagle university of Maryland, colleg park , master of architecture, 2008.

[7] Cynthia K. Chandler,animal assisted therapy in councelling, $3^{\text {rd }}$ ed.(routledge,2017)

[8] Aristide h. esser, behaviour and environment: the use of space by animal and men (New York - London : plenum press, 1971.

[9] Christine Nickl-wheler and Hand nickle, healing architecture(Munich, Braun, 2013)

[10] Indian military code of standards from 1995.

[11] Time savers standards for building types $2^{\text {nd }}$ edition by Joseph De Chiara and John Callender.
[12] Compendium of norms for designing of hospitals and medical institutions.

[13] Planning norms and standards for health facilities (mpd 2021)

[14] Code of standards for veternary clinics and hospitals for small companion animals, dept of agri. as per ao. s.s. 1999 .

[15] The dogs mind- understanding your dogs behaviour - by Bruce Fogel,D.V.M.,M.R.C.V.S. 